\title{
O polissacarídeo do Anacardium occidentale L. na fase inflamatória do processo cicatricial de lesões cutâneas
}

\author{
The polysaccharide from Anacardium occidentale $L$. in the inflammatory phase \\ of the cutaneous wound healing.
}

\author{
Giuliana Viegas Schirato ${ }^{1}$ Flaviane Maria Florêncio Monteiro ${ }^{2}$ Flávio de Oliveira Silva ${ }^{2}$ \\ José Luís de Lima Filho ${ }^{3}$ Ana Maria dos Anjos Carneiro Leão ${ }^{4}$ \\ Ana Lúcia Figueiredo Porto
}

RESUMO

$O$ efeito do polissacarídeo de Anacardium occidentale L. (POLICAJU) foi avaliado na fase inflamatória do processo cicatricial em camundongos (Mus musculus) Swiss $(n=90)$, organizados de acordo com o tratamento empregado: Grupo I ( $\mathrm{NaCl} 150 \mathrm{mM}$ ), Grupo II (ácido ascórbico $75 \mathrm{mg}^{\mathrm{ml} l^{-1}}$ ) e Grupo III (emulsão contendo POLICAJU 150mg. $\mathrm{ml}^{-1}$ preparado em ácido ascórbico $75 \mathrm{mg}^{\mathrm{m}} \mathrm{ml}^{-1}$ ). As lesões cutâneas foram realizadas assepticamente na região torácica dorsal $e$ cada ferida foi tratada em dose única $(200 \mu l)$ imediatamente após a cirurgia. As feridas foram avaliadas diariamente sob o ponto de vista clínico e histopatológico até o $6^{\circ}$ dia de pósoperatório $(P O)$. No $5^{\circ}$ dia $P O$, observou-se um menor percentual de edema e hiperemia no Grupo III em relação aos grupos controle, ao passo que os valores de área da ferida e do percentual de contração não foram estatisticamente significativos. A avaliação histopatológica do grupo tratado com POLICAJU demonstrou a presença de tecido de granulação fibrovascular no 6- dia PO, enquanto os grupos controle apresentavam tecido de granulação com padrão vascular. $O$ tratamento proposto propiciou sinais flogísticos menos acentuados (edema e hiperemia) durante o período inflamatório, compatível com o processo de reparação mais avançado do ponto de vista histopatológico, sugerindo a possível utilização clínica da emulsão contendo POLICAJU.

Palavras-chave: cicatrização, inflamação, biomateriais, polissacarídeo, Anacardium occidentale L. goma do cajueiro.

\section{ABSTRACT}

The effect of the polysaccharide from Anacardium occidentale L. gum (POLICAJU) was evaluated in the inflammatory phase of the wound healing in Swiss mice (Mus musculus) ( $n=90)$, divided according to the employed treatment: Group I ( NaCl 150mM), Group II (75mg.mlascorbic acid) and Group III (emulsion containing 150mg. $\mathrm{ml}^{-1}$

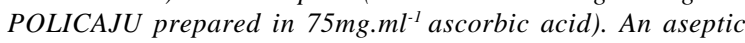
wound was produced in the dorsal thoracic area and each wound was treated in a single dose $(200 \mu l)$ soon after the accomplishment of the lesions. Daily, the wounds were submitted to the clinical and histopathological evaluation until the 6th day of postoperative (PO). In the 5th day PO, the Group III presented the signs oedema and hyperemia, in smaller percentile than the control groups. The results of area of the wound and percentile of contraction didn't obtain statistical significance. The histopathological evaluation revealed, in the 6th day PO, that the Group III presented fibrovascular granulation tissue, while the control groups presented vascular granulation tissue. The use of POLICAJU propitiated to the animals of the treated group inflammatory signs less accentuated (oedema and hyperemia) in the inflammatory period, compatible with the normal wound healing process under the point of view histopathological, suggesting the possible clinical employment of the POLICAJU emulsion.

Key words: wound healing, inflammation, biomaterials, polysaccharide, Anacardium occidentale $L$. cashew gum.

\section{INTRODUÇÃO}

O processo cicatricial envolve uma complexa seqüência de eventos celulares e bioquímicos com o objetivo de restaurar a integridade tecidual após o trauma. Este processo caracteriza-se pela homeostase,

${ }^{1}$ Programa de Pós-graduação em Ciências Biológicas, Universidade Federal de Pernambuco (UFPE), Recife, PE, Brasil.

${ }^{2}$ Programa de Pós-graduação em Ciência Veterinária, Universidade Federal Rural de Pernambuco (UFRPE), Recife, Pernambuco, Brasil.

${ }^{3}$ Departamento de Bioquímica/ Laboratório Imunopatologia Keizo Asami - LIKA (UFPE), Recife, Pernambuco, Brasil.

${ }^{4}$ Departamento de Morfologia e Fisiologia Animal (UFRPE). Rua Dom Manoel de Medeiros s/n - Universidade Federal Rural de Pernambuco, Dois Irmãos, Recife - PE, Brasil. CEP 52171-900. E - mail: analuporto@yahoo.com.br. Autor para correspondência. 
inflamação, formação de tecido de granulação, reepitelização e remodelação da matriz extracelular. Durante a fase inflamatória, são observados infiltrados celulares (neutrófilos, linfócitos e macrófagos), cuja participação é fundamental para regular o processo de reparação, pois secretam citocinas, linfocinas e fatores de crescimento, que atuam como sinalizadores moleculares. Os neutrófilos são as primeiras células recrutadas, aparecendo aproximadamente 24 horas após a lesão, com funções de fagocitose e debridamento de tecidos necrosados, para minimizar a possibilidade de infecção ocasionada por patógenos (STEENKAMP, et al., 2004; PARK \& BARBUL, 2004).

Os macrófagos migram ao local da ferida em cerca de 48 a 96 horas, tornando-se a população celular predominante antes da migração e proliferação dos fibroblastos. Sua ação antimicrobiana ocorre devido à geração de radicais reativos, como óxido nítrico e peróxido de oxigênio. Uma importante contribuição dos macrófagos para o processo cicatricial é a secreção de citocinas e fatores de crescimento, os quais ativam e recrutam outras células envolvidas no processo cicatricial (outros macrófagos e linfócitos), regulam a quimiotaxia e a proliferação de fibroblastos, a síntese de colágeno, além da migração e replicação das células endoteliais, também envolvidas no processo de reparação tecidual (STEENKAMP, et al., 2004; PARK \&BARBUL, 2004).

Para otimizar a reabilitação de lesões, podese utilizar biomateriais, compreendidos como materiais interativos capazes de estabelecer uma afinidade apropriada com o tecido vizinho sem indução de uma resposta adversa do hospedeiro (RATNER \& BRYANT, 2004). Os polissacarídeos estimulam o sistema imune in vitro e in vivo e contribuem favoravelmente no processo cicatricial, podendo ser utilizados como biomateriais (DIALLO, et al., 2001; UENO, et al., 2001; KWEON, et al., 2003; SENEL \& McCLURE, 2004). O heteropolissacarídeo proveniente da goma do Anacardium occidentale L. (POLICAJU) vem sendo utilizado em diversas pesquisas e tem apresentado resultados terapêuticos satisfatórios, potencializando, em estudos preliminares, o processo de cicatrização de lesões cutâneas em camundongos (SCHIRATO et al., 2003; PAIVA, 2003).

O objetivo deste trabalho foi avaliar o efeito do tratamento tópico de lesões cutâneas, em dose única, utilizando-se a emulsão contendo POLICAJU na evolução da fase inflamatória do processo cicatricial cutâneo, do ponto de vista clínico e histopatológico.

\section{MATERIAL E MÉTODOS}

A goma de Anacardium occidentale L. foi coletada no litoral sul do Estado de Pernambuco (Praia de Tamandaré), Brasil. O POLICAJU foi obtido de acordo com o método de MENESTRINA et al. (1998). A emulsão foi formulada adicionando-se ácido ascórbico (1500mg) e POLICAJU (3000mg) à água destilada estéril (10ml) e mantida sob agitação até completa solubilização. $\mathrm{O}$ pH da emulsão foi ajustado em pH 5,0 adicionando-se $\mathrm{NaOH} 1 \mathrm{~N}$. O volume final foi aferido, obtendo a emulsão de concentração final de $150 \mathrm{mg} \cdot \mathrm{ml}^{-1}$ de POLICAJU.

Este estudo foi conduzido de acordo com as normas preconizadas pelo Canadian Council Animal Care (CCAC) e o protocolo experimental foi aprovado pelo Comitê de Ética de Utilização Animal do Centro de Ciências Biológicas, Universidade Federal de Pernambuco. Foram utilizados 90 camundongos (Mus musculus) Swiss, fêmeas, com 8 a 10 semanas de vida e pesando $30,0 \pm 5,0 \mathrm{~g}$, procedentes do biotério do Laboratório de Imunopatologia Keizo Asami (LIKAUFPE), onde os mesmos foram mantidos e acompanhados durante os 6 dias de experimento em ambiente com temperatura, umidade e luminosidade controlados. Os animais foram alimentados com ração específica para roedores e água ad libitum.

Para realização do procedimento cirúrgico experimental, os camundongos foram previamente anestesiados com cloridrato de xilazina $2 \%$ e cloridrato de cetamina $10 \%\left(10 \mathrm{mg} . \mathrm{Kg}^{-1}\right.$ e $115 \mathrm{mg} . \mathrm{Kg}^{-1}$, respectivamente), por via subcutânea (HALL \& CLARKE, 1991). Após a anestesia, realizaram-se a tricotomia e a anti-sepsia da região dorsal torácica com iodopovidona e solução salina estéril $\mathrm{NaCl} 150 \mathrm{mM}$. A pele foi demarcada usando-se um molde de papel adesivo $\left(1 \mathrm{~cm}^{2}\right)$, previamente esterilizado e a ferida cutânea asséptica foi produzida por incisão da pele com lâmina de bisturi número 15 e a divulsão da tela subcutânea foi realizada com tesoura de pontas tipo romba/romba e pinça de dissecção, até sua total ressecção.

Após a realização do procedimento cirúrgico, os animais foram aleatoriamente organizados em grupos ( $\mathrm{n}=30$ /grupo), de acordo com o tratamento: Grupo I ( $\mathrm{NaCl} 150 \mathrm{mM}$ ), Grupo II (ácido ascórbico 75 mg.ml-1) e Grupo III (emulsão contendo POLICAJU 150mg.ml-1). Imediatamente após a cirurgia cada ferida de cada grupo foi tratada, com aplicação tópica, em dose única de 200 $\mu l$ da substância de acordo com o grupo, e o processo cicatricial ocorreu por segunda intenção.

As feridas foram avaliadas diariamente até o $6^{\circ}$ dia de pós-operatório (PO) sob o ponto de vista clínico, evidenciando-se os sinais flogísticos edema, hiperemia, presença de crosta e exsudato, além da mensuração da área, com auxílio de um paquímetro. A contração da lesão foi avaliada através do cálculo da área da ferida, utilizando-se da equação descrita por PRATA et al. (1988): A= p. R. r, onde “A” representa a área, "R" o raio maior e " $r$ " o raio menor da ferida. $O$ 
cálculo do grau de contração da ferida foi expresso como percentual, assim como o índice de cicatrização, utilizando-se as equações propostas por RAMSEY et al. (1995): $100 \times(\mathrm{Wo}-\mathrm{Wi}) / \mathrm{Wo}=\mathrm{M} \pm \mathrm{DP}$, onde Wo $=$ área inicial da ferida; $\mathrm{Wi}=$ área da ferida no dia da

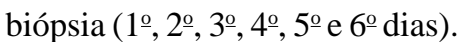

Para realização de estudo histopatológico, os fragmentos de pele foram coletados diariamente e, a cada dia de biópsia, cinco animais foram retirados dos grupos experimentais e, posteriormente, submetidos à eutanasia por superdosagem com Pentobarbital sódico (200mg. Kg ${ }^{-1}$ ), via intra-peritonial. As amostras foram submetidas ao processamento histopatológico, incluídas em parafina e, após microtomia, os cortes foram corados por Hematoxilina Eosina e, alternativamente, pelo Tricrômico de Masson (MICHALANY, 1990).

Os resultados obtidos foram expressos como média \pm desvio padrão $(\mathrm{M} \pm \mathrm{dp})$, submetidos à análise de variância e ao teste de Tukey, aceitando-se como estatisticamente significativos os valores comparados ao nível de significância de 5\%.

\section{RESULTADOS E DISCUSSÃO}

As lesões experimentais dos camundongos foram avaliadas do ponto de vista clínico ao longo de seis dias de experimento. A avaliação macroscópica das feridas permitiu evidenciar sinais flogísticos menos acentuados no grupo tratado quando comparados aos dos grupos controle. O edema, conseqüente ao acúmulo de fluído e proteínas plasmáticas no espaço extravascular em resposta à ação de citocinas, foi observado em todos os grupos estudados. Entretanto, a sua freqüência foi menor nas lesões tratadas com POLICAJU (33\%), especialmente no 4 dia de avaliação clínica, comparada aos Grupos I e II (86,67\% e 86,67\%, respectivamente). De forma semelhante, a hiperemia foi observada ao longo de todo o período avaliado. Vale ressaltar que, no 5ํ e $6^{\circ}$ dias de pós-operatório, foi evidenciado um menor percentual no Grupo III ( $60 \% \mathrm{e}$ $40 \%$, respectivamente). No mesmo período, as lesões nos camundongos do Grupo I, tratadas com solução salina, apresentaram hiperemia em $100 \%$ deles.

A partir de 24 horas após a realização das lesões experimentais, $100 \%$ das feridas em todos os grupos apresentaram formação de crosta. No último dia de avaliação, observou-se desprendimento de crosta em 20\% dos animais pertencentes ao Grupo I, porém as lesões não se encontravam reepitelizadas, o que não foi evidenciado nos demais grupos estudados. No processo de reparação tecidual, normalmente, ocorre desprendimento da crosta quando a cobertura epitelial está completa. No caso do Grupo I, o desprendimento pode ser atribuído a algum fator extrínseco, já que não havia reepitelização completa do local da lesão.

As características exsudativas da fase inflamatória também foram acompanhadas durante o experimento. No 1ำ dia de pós-operatório, observou-se exsudato de característica serosangüinolenta em $24,14 \% ; 13,79 \%$ e $20 \%$ das feridas dos animais pertencentes aos Grupos I, II e III, respectivamente. As feridas tratadas com solução salina apresentaram exsudato em suas lesões ao longo dos primeiros cinco dias de pós-operatório. No entanto, no 6o dia de pósoperatório, apenas $20 \%$ dos animais do Grupo II (tratado com ácido ascórbico) apresentaram este sinal flogístico. É importante ressaltar que não foi observada secreção purulenta em 100\% das feridas estudadas, já que foram feridas limpas e realizadas cirurgicamente.

A utilização dos polissacarídeos como biomateriais é vantajosa, pois interferem favoravelmente na resposta imune, assim como no processo cicatricial. Quando a atividade antitumoral de polissacarídeos ( $\alpha$-glucana de Ramalina celastri nativa e sulfatada quimicamente) foi testada in vivo frente ao Sarcoma 180, observou-se que o esquema de tratamento em doses fracionadas por 10 dias causou perda da atividade biológica, por desenvolvimento de tolerância ao princípio ativo (STUELP-CAMPELO, et al., 2002). Por esta razão, optou-se por utilizar uma única aplicação da emulsão de POLICAJU. Deve-se ainda ressaltar que o polissacarídeo ácido obtido de Vernonia kotschyana possui efeito estimulante dosedependente da fixação do complemento em humanos, além de possuir efeito mitogênico in vitro (NERGARD, et al., 2004). KWEON, et al. (2003) avaliando o efeito do tratamento com o complexo hidrossolúvel quitosana/ heparina em feridas cutâneas em ratos, observaram que no $15^{\circ}$ dia de pós-operatório, as feridas estavam completamente cicatrizadas com aspecto similar à pele normal. Entre outros fatores, o efeito da quitosana pode ser atribuído à estimulação de citocinas (IL-1, IL-6 e TNF- $\alpha$ ) que auxiliam no processo de reparação tecidual (UENO, el al., 2001). Foi relatado também que o polissacarídeo de Angelica sinensis possui efeito cicatrizante em úlceras gástricas experimentais em ratos Sprague-Dawley, além de possuir efeito estimulante in vitro de proliferação de células epiteliais gástricas (YE, et al., 2003).

Alguns polissacarídeos, como a quitina e a quitosana, vêm sendo utilizados com fins terapêuticos em medicina veterinária, pois atuam como agente cicatrizante, antimicrobiano e hemostático, além de possuir efeito analgésico (SENEL \& McCLURE, 2004). Produtos obtidos do cajueiro (Anacardium 
occidentale) são bastante populares na medicina popular, sendo amplamente empregado no tratamento de doenças inflamatórias na Nigéria, causando redução da síntese de prostaglandinas $(90 \%)$ na vesícula seminal em bovinos (OLAJIDE et al., 2004).

Quanto à evolução da área das lesões (Figura 1), no 1ํ dia de pós-operatório, as feridas dos animais dos Grupos I, II e III apresentavam a área média de 2,29 $\pm 0,41 \mathrm{~cm}^{2} ; 2,32 \pm 0,56 \mathrm{~cm}^{2}$ e 2,45 $\pm 0,43 \mathrm{~cm}^{2}$, respectivamente. Entre o $2^{\circ}$ e $3^{\circ}$ dias de pós-operatório, foi observado aumento da área das lesões dos animais pertencentes a todos os grupos, possivelmente devido ao aparecimento de crosta e edema. A partir do $4^{\circ}$ dia, observou-se redução gradativa das áreas das lesões. No 6o dia de pós-operatório, a área média das lesões dos animais dos Grupos I, II e III foi respectivamente; $2,15 \pm 0,82 \mathrm{~cm}^{2} ; 2,07 \pm 0,57 \mathrm{~cm}^{2} \mathrm{e} 2,14 \pm 0,48 \mathrm{~cm}^{2}$.

Quando os percentuais de contração das lesões foram analisados, observa-se não haver contração nas feridas do Grupo I (solução salina) entre o $1^{\circ}$ e $4^{\circ}$ dias de pós-operatório. Nesse grupo, 5 e 6 dias após a realização das lesões, o percentual de contração foi, respectivamente, $2,20 \%$ e $15,10 \%$. Nas lesões tratadas com ácido ascórbico (Grupo II), até o 5ํ dia de pós-operatório, não ocorreu contração; apenas no $6^{-}$ dia de experimento foi evidenciada contração neste grupo $(7,15 \%)$. Quando as lesões foram tratadas com a emulsão de POLICAJU, observou-se contração nos 5ำ e $6^{\circ}$ dias de experimento, apresentando percentuais de $5,41 \%$ e $15,56 \%$, respectivamente.

Os resultados de área da ferida e percentual de contração obtidos neste experimento não foram estatisticamente significativos (teste de Tukey), em relação ao tratamento utilizado nos grupos experimentais, o que pode ser explicado pela contração da área do tecido de granulação, a qual ocorre, em parte, devido aos miofibroblastos, reduzindo assim o tamanho da área lesada. (STEVENS \& LOWE, 1996). SCHIRATO et al. (2002) não verificaram diferenças significativas de área das feridas tratadas com a emulsão contendo diferentes concentrações de POLICAJU até o 7ํ dia de pós-operatório. Tal fenômeno é esperado, pois na fase inflamatória do processo cicatricial não ocorre redução significativa de área e do percentual de contração da

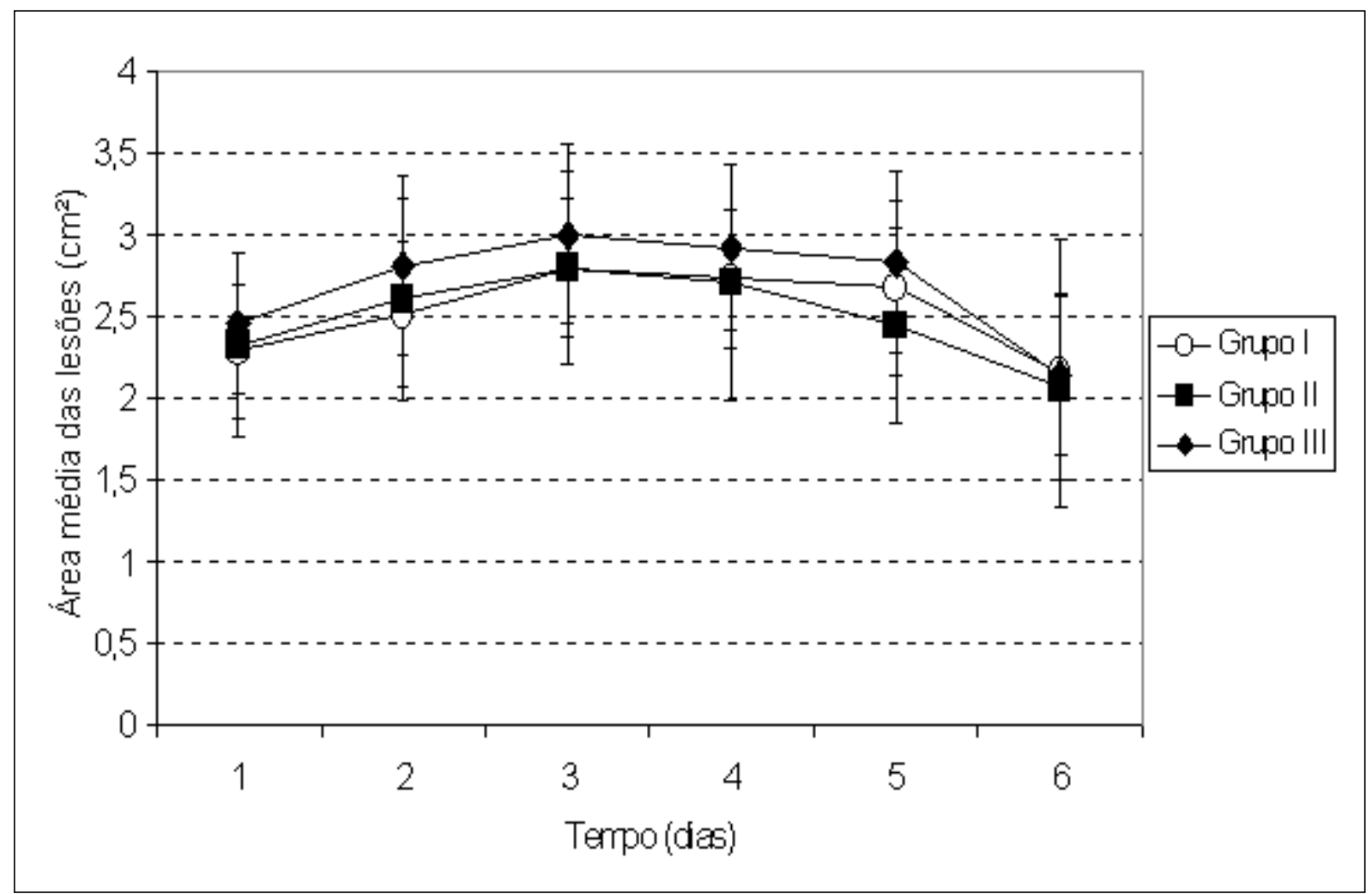

Figura 1 - Área média das feridas experimentais em camundongos dos grupos I (tratado com $\mathrm{NaCl}$ ), II (tratado com ácido ascórbico 75 mg.ml-1) e III (tratado com POLICAJU $150 \mathrm{mg}^{-\mathrm{ml}^{-1}}$ ).

Ciência Rural, v.36, n.1, jan -fev, 2006. 
lesão, devido ao pequeno número de miofibroblastos no local da ferida.

$\mathrm{O}$ aspecto histopatológico das feridas foi semelhante em todos os grupos entre o $1^{\circ}$ e $5^{\circ}$ dias. $\mathrm{O}$ $1^{\circ}$ dia foi caracterizado pela presença de infiltrados polimorfonucleares, ocorrência de angiogênese, além da existência de exsudato e da formação de crosta, ressaltando-se que as crostas dos animais tratados com a emulsão de POLICAJU eram mais delgadas se comparadas às crostas dos grupos controle (solução salina e ácido ascórbico) (Figuras 2A e 2B). No 2을 dia de pós-operatório (Figura 2C), evidenciou-se a presença de tecido de granulação vascular, presença de infiltrado de leucócitos polimorfonucleares, neovascularização e crosta. Entre o 3ํ e o 5o dias de pós-operatório, verificaram-se ainda inúmeros fibroblastos na derme e presença de neovascularização (Figura 2D).

As principais diferenças foram observadas

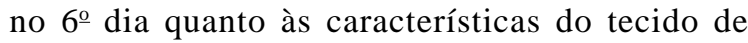
granulação, o qual apresentava um padrão vascular nas feridas dos Grupos I e II. Nas feridas tratadas com emulsão contendo POLICAJU (Grupo III) observou-se a

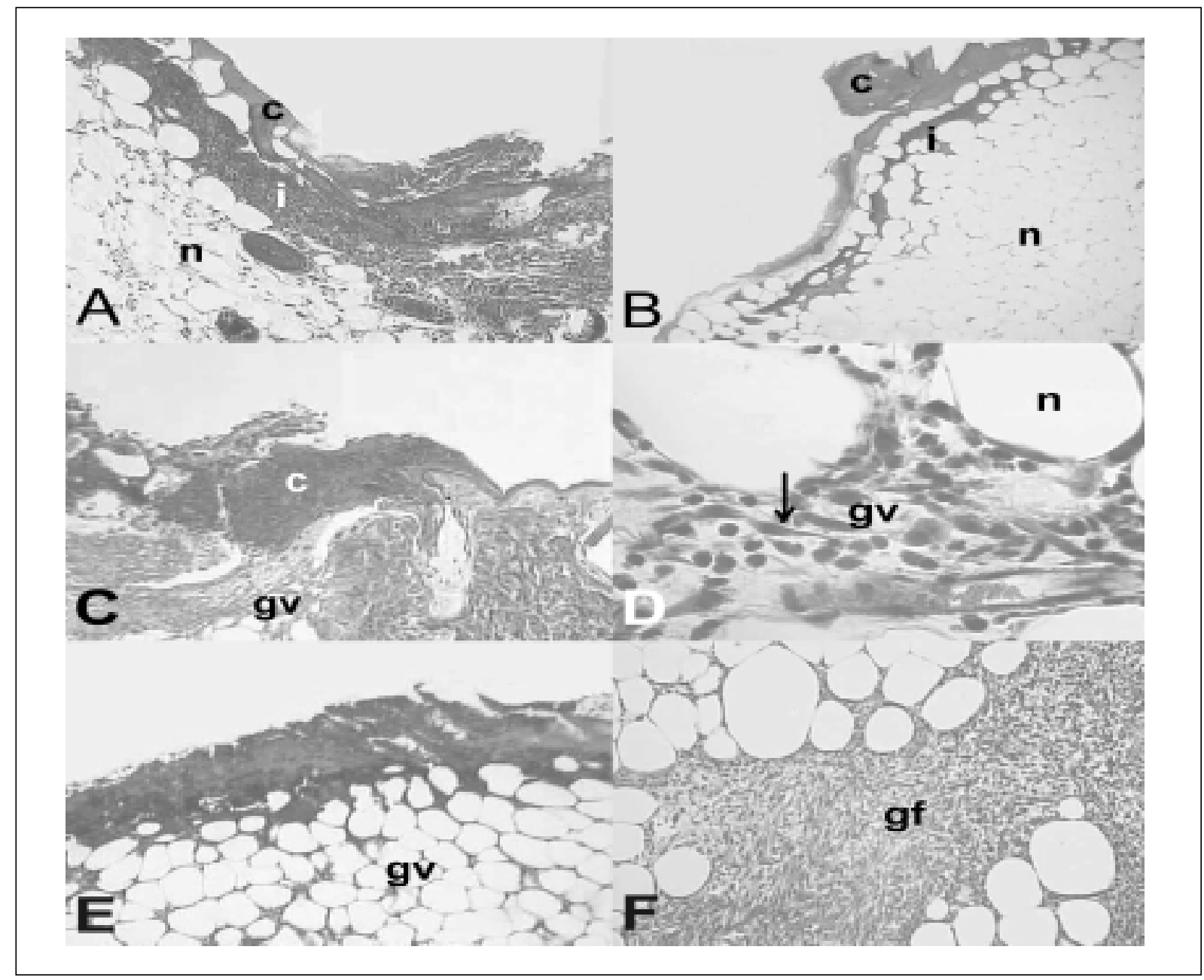

Figura 2 - Aspectos histopatológicos das feridas em camundongos. Tricrômico de Masson. A (100X), Grupo I (tratado com NaCl), $1^{\circ}$ dia de pós-operatório (PO); B (40X), Grupo III (tratado com POLICAJU $150 \mathrm{mg}^{-\mathrm{ml}^{-1}}$ ), $1^{\text {o }}$ dia de PO; C (100X), Grupo I, $2^{\circ}$ dia de PO; D (400X), Grupo I, 3ำ dia de (PO); E (40X), Grupo II (tratado com ácido ascórbico $75 \mathrm{mg}^{\mathrm{ml}} \mathrm{ml}^{-1}$ ), 6o dia de PO e F (100X), Grupo III, 6o dia de PO. Percebe-se em A e B presença de neovascularização, crosta e infiltrado de leucócitos polimorfonucleares. Em C, há tecido de granulação de padrão vascular e crosta espessa. Em D e E evidencia-se tecido de granulação de padrão vascular, inúmeros fibroblastos na derme e neovascularização. Em F, nota-se presença de tecido de granulação fibrovascular, presença de trabéculas de tecido conjuntivo ocasionando áreas de tração no tecido. c - crosta; gv tecido de granulação vascular; $\mathrm{n}$ - neovascularização; gf - tecido de granulação fibrovascular; i-infiltrado de leucócitos polimorfonucleares; $\rightarrow$ - fibroblasto. 
existência de tecido de granulação fibrovasculare presença de trabéculas de tecido conjuntivo, ocasionando áreas de tensão no tecido (Figuras 2E e 2F).

PAIVA (2003), utilizando emulsões aplicadas de forma tópica, contendo diferentes concentrações de POLICAJU em lesões experimentais em camundongos, para avaliar a progressão do processo reparativo (até o $12^{\circ}$ dia), evidenciou sinais flogísticos menos intensos nos grupos tratados comparados aos controles. No 7ํㅡ dia de pós-operatório, também observou a presença de tecido de granulação de padrão fibrovascular e intensa angiogênese especialmente no grupo tratado com a emulsão contendo POLICAJU na concentração de $150 \mathrm{mg} \cdot \mathrm{ml}^{-1}$. No $12^{\circ}$ dia de pósoperatório, foi observada a formação de tecido de granulação fibrovascular e a presença de tecido fibroso com pobre organização de fibras colágenas nos grupos tratados com solução salina e ácido ascórbico (controles). Já as feridas tratadas com a emulsão POLICAJU 150mg. $\mathrm{ml}^{-1}$, demonstraram, neste período, tecido de granulação com fibras colágenas bem organizadas e total reepitelização.

\section{CONCLUSÃO}

Com base nos resultados obtidos, pode-se concluir que a emulsão contendo POLICAJU $150 \mathrm{mg} \mathrm{ml}^{-1}$ favorece a resolução do período inflamatório, considerando as características de sinais flogísticos menos intensos e a presença de tecido granulação fibrovascular e fibras colágenas, em relação aos grupos controle (tratados com $\mathrm{NaCl}$ e ácido ascórbico 75mg. $\mathrm{ml}^{-1}$ ).

\section{AGRADECIMENTOS}

Aos órgãos de fomento BNB, FACEPE, CNPq, FINEP e CAPES, pelo suporte financeiro.

Ao Programa Institucional de Bolsas de Iniciação Científica/Conselho Nacional de Desenvolvimento Científico e Tecnológico (PIBIC/ CNPq), Universidade Federal Rural de Pernambuco (UFRPE), por conceder a bolsa de iniciação científica a Giuliana Viegas Schirato no período de execução deste trabalho.

\section{REFERÊNCIAS}

DIALLO, D. et al. Polysaccharides from the roots of Entada africana Guill. et Perr., Mimosaceae, with complement fixing activity. Journal of Ethnopharmacology, v.74, p.159-171, 2001 .

HALL, L.W.; CLARKE, K.W. Veterinary anaesthesia. London: Ballière Tindall, 1991. 410p.

KWEON, D.K. et al. Preparation of water-soluble chitosan/ heparin complex and its application as wound healing accelerator. Biomaterials, v.24, p.1595-1601, 2003.

MENESTRINA, J.M. et al. Similarity of monosaccharide, oligosaccharide and polysaccharide structure in gum of Anacardium occidentale L. Phytochemistry, v.47, p.714$721,1998$.
MICHALANY, J. Técnica histológica em anatomia patológica. 2.ed. São Paulo: Michalany, 1990. 277p.

NERGARD, C.S. et al. Isolation, partial characterization and immunomodulating activities of polysaccharides from Vernonia kotschyana Sch. Bip. ex Walp. Journal of Ethnophamacology, v.91, p.141-152, 2004.

OLAJIDE, O.A. et al. Effects of Anacardium occidentale stem bark extract on in vivo inflammatory models. Journal of Ethnopharmacology, v.95, p.139-142, 2004.

PAIVA, M.G. Utilização do polissacarídeo da goma do cajueiro (Anacardium occidentale L.) em cicatrização experimental. 2003. 56f. Dissertação (Mestrado em Bioquímica) - Curso de Pós-graduação em Bioquímica, Universidade Federal de Pernambuco.

PARK, J.E.; BARBUL, A. Understanding the role of immune regulation in wound healing. American Journal of Surgery, v.187, p.11S-16S, 2004

PRATA, M. et al. Uso tópico do açúcar em feridas cutâneas, estudo experimental em ratos. Acta Cirúrgica Brasileira, v.3, n.2, p.43-48, 1988.

RAMSEY, D.T. et al. Effects of three occlusive dressing materials on healing of full-thickness skin wounds in dogs. American Journal of Veterinary Research, v.56, n.7, p.941-949, 1995.

RATNER, B.D.; BRYANT, S.J. Biomaterials: where we have been and where we are going. Annual Review of Biomedical Engineering, v.6, p.41-75, 2004.

SCHIRATO, G.V. et al. Application of the polysaccharide from cashew gum in the rehabilitation of experimental cutaneous lesions in mice. In: REUNIÃO ANUAL DA SOCIEDADE BRASILEIRA DE BIOQUÍMICA E BIOLÓGICA MOLECUlAR, 32., 2003, Caxambu, Minas Gerais. Anais... São Paulo: Sociedade Brasileira de Bioquímica e Biologia Molecular, 2003. p. 100

SCHIRATO, G.V. et al. Utilização do polissacarídeo da goma do cajueiro (Anacardium occidentale L.) como biomaterial na reepitelização de lesões cutâneas experimentais em camundongos In: JORNADA DE ENSINO, PESQUISA E EXTENSÃO, 2., 2002, Recife, PE. Anais... Recife: Universidade Federal Rural de Pernambuco, 2002. 1 CD.

SENEL, S.; McCLURE, S.J. Potential applications of chitosan in veterinary medicine. Advanced Drug Delivery Reviews, v.56, p.1467-1480, 2004.

STEENKAMP, V. et al. Studies on antibacterial, antioxidant and fibrobast growth stimulation of wound healing remedies from South Africa. Journal of Ethnopharmacology, v.94, p.353-357, 2004.

SteVens, A.; LOWE, J. Patologia. São Paulo: Manole, 1996. 535p.

STUELP-CAMPELO, P.M. et al. Effect of a soluble alfa-Dglucan from the lichenized fungus Ramalina celastri on macrophage activity. International Immunopharmacology, v.2, p.691-698, 2002.

UENO, H. et al. Topical formulations and wound healing applications of chitosan. Advanced Drug Delivery Reviews, v.52, p.105-115, 2001.

YE, Y.N. et al. Effect of polysaccharide from Angelica sinensis on gastric ulcer healing. Life Sciences, v.72, p.925-932, 2003 . 